\title{
Deodorization of water at water treatment plants in the lower Volga with activated anthracite
}

\author{
Liudmila Boronina ${ }^{1, *}$, Russlan Israilov ${ }^{2}$ and Valerii Fomichev ${ }^{3}$ \\ ${ }^{1}$ Astrakhan State University of architecture and Civil Engineering, Department of utility systems and \\ ecology, 414056, Astrakhan, Tatischeva str., Russia \\ ${ }^{2}$ Platov South-Russian State Polytechnic University, Department of Water management, utilities and \\ environmental protection, 346428, Prosveshcheniya St. 132, Rostov region, Novocherkassk, Russia \\ ${ }^{3}$ Volgograd State Technical University, Department of Water supply and sanitation, 400005, \\ Volgograd, Lenin avenue, 28, Russia
}

\begin{abstract}
The need for deodorization of the Volga water during the development of blue-green and diatom algae is shown. Most often there is a smell that is characterized as moldy, earthy, sometimes fishy, these odors are caused by geosmin and 2-methylisoborneol, which are products of the metabolism of microorganisms, mainly cyanobacteria and actinomycetes, as well as many microalgae species. Presented are the results of laboratory and pilot studies of water carbonation using Donbas activated anthracite and wood powder sorbent of SPDK brand in the experimental setup. Prospectivity of water deodorization in the lower Volga flow is determined by the sorption method using powdered activated carbon (PAC) obtained by activating the anthracites of the coal deposit Obukhovskiy, Rostov Region. Pilot tests of water purification on the experimental setup showed the effectiveness of PAC application on the basis of the activated anthracite of the Gukovsky deposit, with the optimal dose of PAC being $15-25 \mathrm{mg} / 1$ with a dose of 20-30 mg / 1 coagulant aluminum oxychloride.
\end{abstract}

\section{Introduction}

In some years in the summer-autumn period, there are a musty, earthen, moldy smell of water in the city water supply stations of Astrakhan, Akhtubinsk, Krasny Yar and other with a water intake from the Volga River and Akhtuba and Buzan. The presence of substances that impart an unpleasant smell and taste to household and drinking water causes reasonable claims and complaints from consumers. The presence of these substances is most often associated with natural processes - the active growth and metabolism of organisms in sources of drinking water. Thus, according to research in the summer, the concentration of phytoplankton exceeds the permissible standard for sources of centralized domestic and drinking water supply (GOST 2761-84) rises more than 3 times, the concentration of microalgae on separate days exceeds 300,000 cells / cm3 [1].

\footnotetext{
* Corresponding author: boroninalv@gmail.com
} 
Microphytes are present in the water of Volga River during all periods of the year and they are represented mainly by diatoms (Coscinodiscus radiatus), blue-green algae (M. grevillei) and green algae (Mougeotia sp.), With yearly growth of the number of microalgae cells and changes in their species composition [2-3].

Most often there is a smell, characterized as moldy, earthen, sometimes observed fish. This is primarily due to compounds such as 2-methylisoborneol and geosmin, which are products of metabolism of a number of microorganisms, mainly cyanobacteria and actinomycites, as well as many species of microalgae [4]. These microorganisms are included in aquatic biocenoses and are closely associated with the development of phytoplankton.

\section{Direction of research}

Deodorization of water can be achieved by coagulation and flocculation of impurities, followed by filtration, but to eliminate unwanted odors and flavors inherent in the water source of Volga River in the summer and characterized by high resistance, requires the use of special technologies. Universal methods of deodorization of water today does not exist, however, the use of some of them in combination provides the required degree of purification. Odors and flavors caused by organic matter, removed by adsorption, which uses activated anthracite, powdered and granular activated carbon (AC), carbon fiber materials and carbon sorbents (clinoptilolite, zeolites, etc.). Activated carbon is made from carbonaceous materials: peat, coconut shell, wood, anthracite, coal, etc. Milled to the size of 10-100 microns and sorted raw materials are usually carbonated in drum furnaces without air access at a temperature of $700-800^{\circ} \mathrm{C}$, as a result of which volatile compounds are released from coal, it is compacted, acquires strength and macroporous structure. Coal activate with gases $(\mathrm{O} 2, \mathrm{SO} 2, \mathrm{CO} 2)$ at a temperature of $750-1000^{\circ} \mathrm{C}$. Most often, a combined steam-gas method with flue gases of $\mathrm{CO} 2+\mathrm{H} 2 \mathrm{O}+\mathrm{O} 2$ is used. Inorganic activating additives are washed out of the coal.

The sorption method is more reliable than the oxidizing one, since it is based not on the destruction of organic substances, but on their extraction from water. Activated carbons can be used in two ways: filtration through granulated coal and introduction of powdered coal (carbonization) into the treated water. More common is the use of granular AC as a filter feed. Such filters, regardless of fluctuations in the level of water pollution, serve as a permanent barrier to sorption substances. However, a serious difficulty of this method of deodorization of water in the conditions of the water supply of Volga River is a relatively small absorption capacity of AC. This causes the need for frequent replacement or regeneration, as well as the lack of space at the filter stations (and lack of funds) for the placement of sorption filters of the III stage of water purification. The filling of the existing fast sand filters with the second layer of granulated AC will cause difficulties when washing such filters. Due to the difference in the volume of loads weights, the lower filter layer will not go into a suspended state and eventually clamped. The increase in the intensity of washing with washing water will make the entire layer of AC.

Despite a number of existing disadvantages of carbonation of water (powdered AC dusts, constant dose adjustment in accordance with the concentration and type of odorants, difficulties soaking and dosing of pulp, explosive, etc.) it has been found practical application, especially in cases where deodorization should be made periodically, in small doses of $\mathrm{AC}$ and briefly, which is required for seasonal carbonation of water of Volga River.

Until now, powdered activated carbon (PAC) has not been used or studied in the water supply systems of Volga River, so there are no practical recommendations on the technological parameters at the water supply stations of the lower Volga (contact time, 
entry points, dose, PAC grade, etc.). To study this problem, at the first stage, laboratory studies were conducted to study the sorption of odorant compounds from raw water of the Volga River by carbon sorbents of the following PAC brands: SPDK; crushed anthracite of the «Mayskaya» mine; NWC; samples No.1-4.

The studies were carried out on the water of the Volga River and Akhtuba according to the following scheme: $1,5 \mathrm{dm}^{3}$ of the initial raw water was poured into the glass, put on a magnetic stirrer and added pre-prepared pulps of the studied PAC samples with doses of $15 \mathrm{mg} / \mathrm{dm}^{3}$ for each experiment. During mixing, the permanganate oxidation (PO) was determined in filtered samples. After $2.5 \mathrm{~h}$ of mixing water with PAC was added coagulantaluminum oxychloride brand " Aurat TM-30" dose of $30 \mathrm{mg} / \mathrm{dm}^{3}$ and after the deposition of the suspension was also determined by PO. The kinetic curves obtained from the five time points are shown in figure 1.

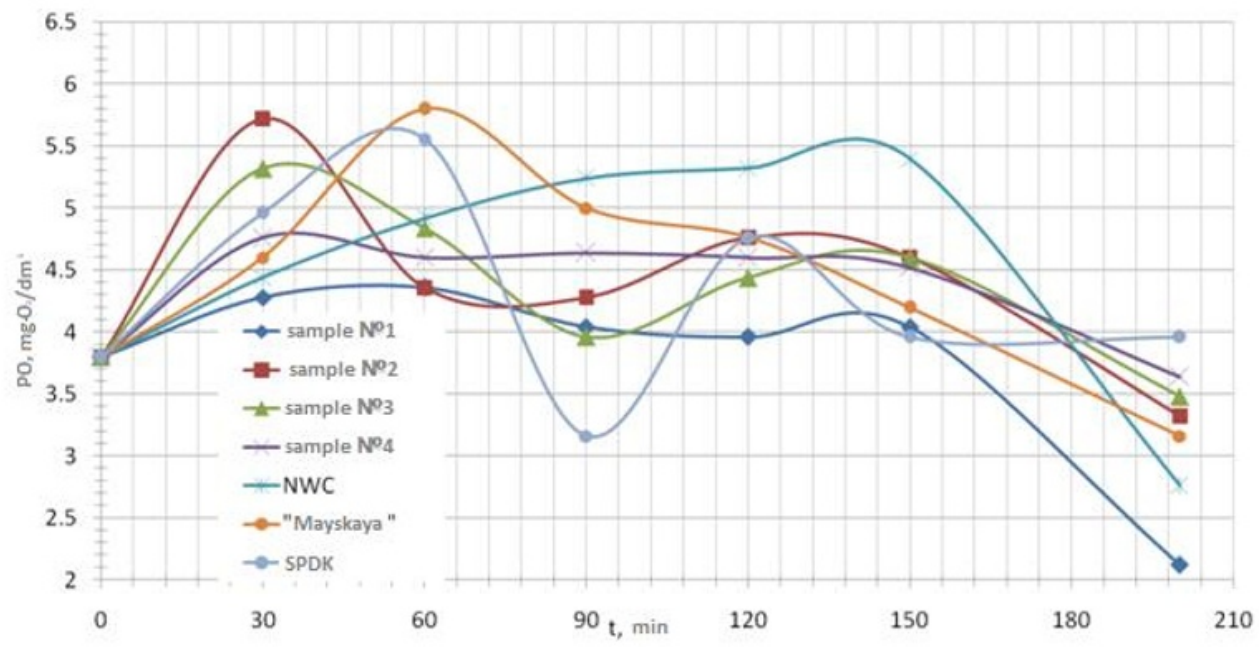

Fig. 1. Permanganate oxidation of the raw water at the time of contact with the sorbents. Doses: carbon sorbent-15 mg/ 1; aluminum oxychloride-30 mg/l.

As follows from the presented graphs, the best indicators in terms of the quantity of the PO are demonstrated by sample No.1, which is especially evident after water coagulation. Increase in PO in the first 30 minutes due to the presence in the pores of PAC phenols formed after the activation of coal.

With the aim of experimental verification of the efficiency of sorption removal of source water contaminants, causing odors and flavors, it was experimental dosing of PACs (sample No.1 and PAC brand SPDK) with subsequent coagulation in the sludge blanket and filtration in the model rapid filter. The tests were carried out in the laboratory at the treatment facilities of the city of Akhtubinsk in the period from July to August 2018. The technological scheme of the experimental setup modeled the composition of structures, which include: a vertical mixer, clarifiers with a layer of suspended sediment, fast filters. Of reagents used chlorination with ammoniacal and coagulant - aluminium oxychloride "Aurat TM-30". The structure of the installation included: contact tank with a propeller stirrer, simulating the residence time of raw water $(15 \mathrm{~min})$ in the water pipe from the intake to the site of treatment facilities, mixer-aerator for the most complete mixing of reagents (PAC, ammonium sulfate, electrolysis sodium hypochlorite (SHC), "Aqua-Aurat TM-30") with water; the clarifier with a suspended sludge layer of the "Hirzer", in the middle of which was formed and accumulated in the sludge blanket of flakes of aluminum 
hydroxide, rapid filter with granular loading of the sorption filter material of ODM-2F Technological scheme presented in figure 2 .

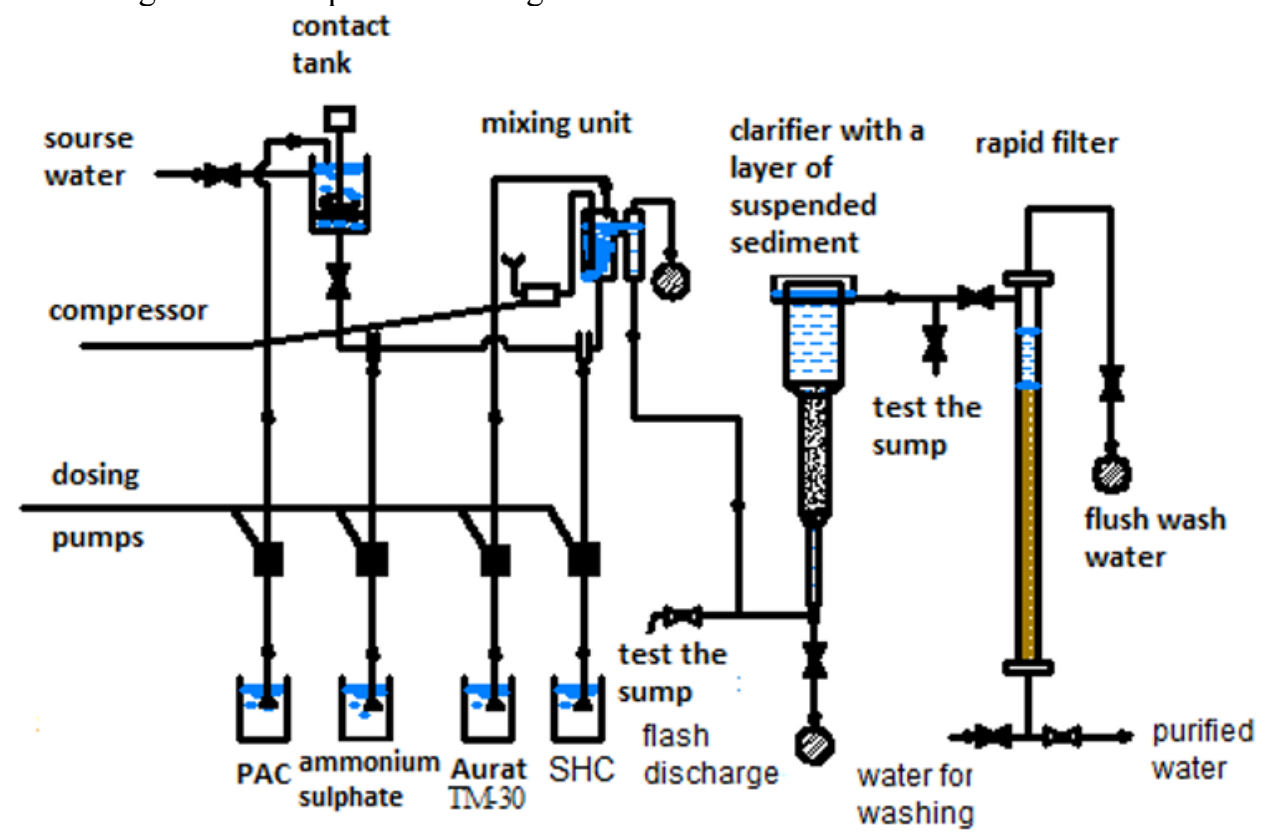

Fig. 2. Technological scheme of the experimental system of water deodorization.

The clarifier with a suspended sludge layer or precipitator of the type "Grazer" [5] consists of three stacked on top of each of the cylinders of increasing diameter interconnected truncated cones. The bottom-up water flow rates are taken so that there is no sedimentation of the suspension in the lower part (V2,0-2,5 mm/s), and in the upper part there is no sediment removal into the clarified water (V0,2-0,3 mm/s). The flow rate in the middle part $(\mathrm{V} 0,8-1,0 \mathrm{~mm} / \mathrm{s})$ provides a hydrodynamic equilibrium of the suspended sediment layer. Sediment as filling was removed. The unit is also equipped with a single membrane dispenser brand ETATRONDS-ROME type DLX with a flow rate of up to $5 \mathrm{l} / \mathrm{h}$ for the supply of ammonium sulfate solution (NH4)2SO4 and three peristaltic pumps ETATRONDS-ROME type B-VIRATACQUE with a flow rate of 2 to $5 \mathrm{l} / \mathrm{h}$. The performance of the experimental setup of $40 \mathrm{l} / \mathrm{h}$ or $0.7 \mathrm{l} / \mathrm{min}$ After each structures setup, you have the sampler. To work with the installation was prepared PAH pulp sample No.1 and SPDC concentrations of $0.035 \%$, as well as solutions: $0.003 \%(\mathrm{NH} 4) 2 \mathrm{SO} 4 ; 0.1 \%$ $\mathrm{NaClO}$ and $0.1 \% \mathrm{Al} 2(\mathrm{OH}) 5 \mathrm{Cl}$.

The scheme of operation of the installation is as follows: the initial raw water was supplied to the contact container, with a propeller stirrer installed, eliminating the settling of the AU slurry dosed into the tank. From the contact tank, raw water with PAH is gravity fed into the mixer, into the pipeline to which ammonium sulfate, sodium hypochlorite and coagulant are dosed in series. After the mixer, water with reagents passes the clarifier with a layer of suspended sediment and then goes to the fast filter. During the tests, PAH doses from 0 to $40 \mathrm{mg} / \mathrm{l}$ and coagulant from 10 to $40 \mathrm{mg} / \mathrm{l}$ were varied. The dose ratio (NH4)2SO4 (for NH4) and $\mathrm{NaClO}$ (for active chlorine) was 1:5, the flow rates of the dispensers were adjusted for the residual chlorine after the filter and maintained equal to: $0.2 \mathrm{mg} / \mathrm{l}$-active I1,0 mg/l-active bound chlorine. The decline in plavanii Volga water with the use PAH "Termolat" sample No. 1 and the SCAP is shown in Fig.3 from which it 
follows that the best results were obtained with the use in the scheme deodorization PAH sample No. 1 produced by "Termolat" at doses of PAHs $15 \mathrm{mg} / \mathrm{l}$ of coagulant $20 \mathrm{mg} / \mathrm{l}$.

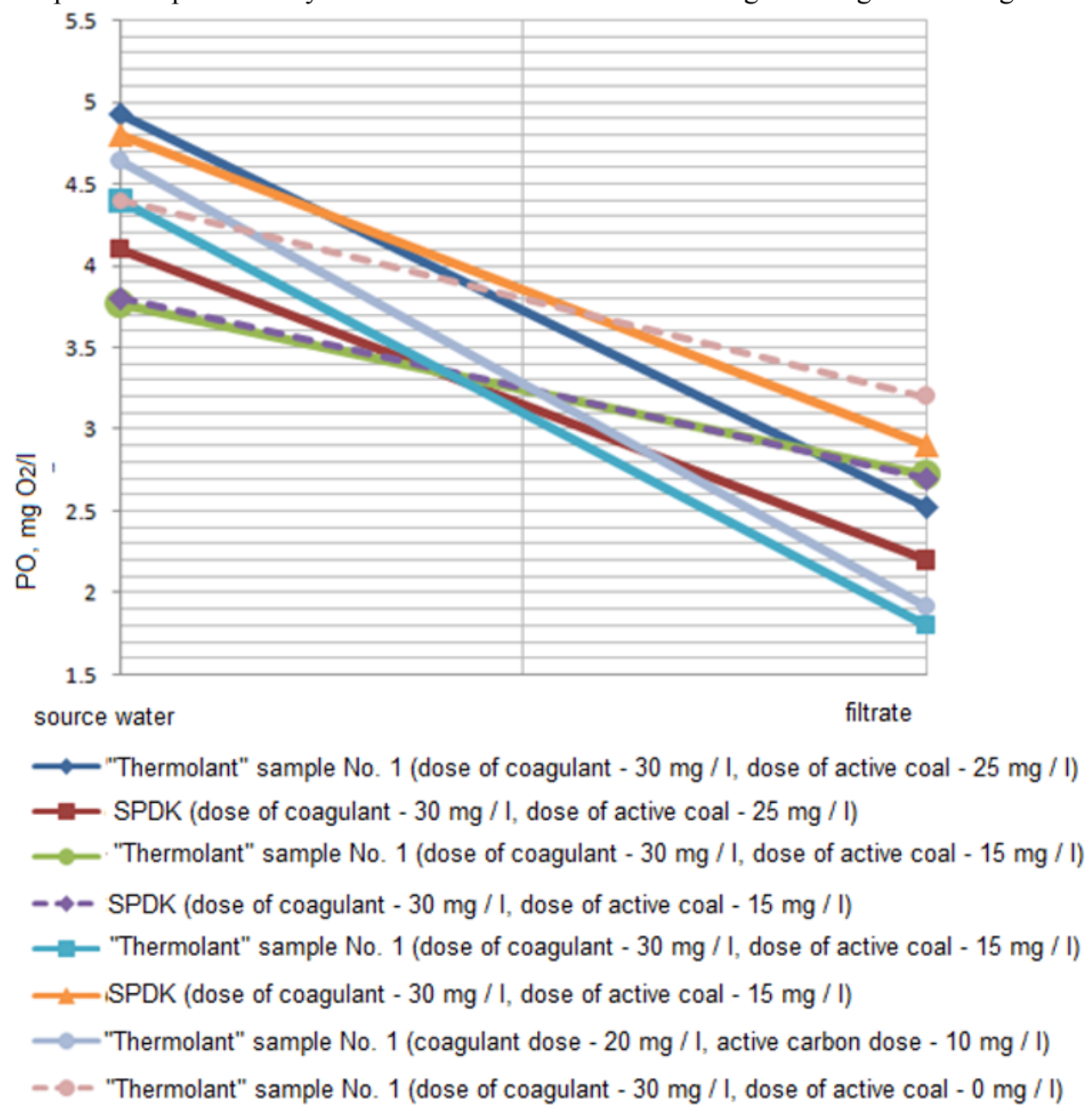

Fig.3. Reduction of permangonate oxidability for PAC samples.

An increase in the doses of PAC and coagulant was not observed above these deodorization effects. At the established optimum doses of PAC "Thermolant" and aluminum oxychloride, smells and flavors in the filtrate of the experimental setup were not available, unlike the drinking water that was purified at the water treatment facilities in the city of Akhtubinsk according to the traditional two-stage scheme without the coaling phase.

\section{Conclusions}

1. Odors that periodically appear in the Volga water and its tributaries near the city of Astrakhan and other large cities of the Astrakhan region are due to the presence of diatoms, blue-green and green algae.

2. Prospectivity of water deodorization in the lower reaches of the river was established. Volga method of sorption using PAH, obtained by activating the anthracite coal basin of the Rostov region. 
3. Water purification tests on the experimental setup showed the effectiveness of the use of $\mathrm{PAH}$, with the optimal dose of PAH being $15-25 \mathrm{mg} / \mathrm{L}$ with a coagulant dose of aluminum oxychloride 20-30 mg / L

\section{References}

1. L.V. Boronina, Water purification, 9 63-70 (2011)

2. GOST 2761-84 Sources of centralized household and drinking water supply. Hygienic, technical requirements and selection rules. (Moscow: IPK Publishing House of Standards, 2001)

3. Practical hydrobiology. Freshwater ecosystems (Moscow: PIM, 2006)

4. L.V. Boronina, Water supply and sanitary engineering, 12 10-15 (2012).

5. Technical notes on water (Moscow: Stroiizdat, 1983)

6. L.V. Boronina, Water resources, 43(4) 419 (2016).

7. L.V. Boronina, Materials of the XII International Scientific and Practical Conference, dedicated to the memory of academician of the RAS S.V. Yakovleva, MSSU, 24-30 (2017) 